\title{
Modification of Grout Properties in Prepacked Aggregate Concrete Incorporating Palm Oil Fuel Ash
}

\author{
Reza Hodjati, Hossein Aslani, Iman Faridmehr, A. S. M. Abdul Awal, and Ziba Kazemi \\ Faculty of Civil Engineering, Universiti Teknologi Malaysia, 81310 Skudai, Johor, Malaysia \\ Correspondence should be addressed to Reza Hodjati; rezahodjati670@gmail.com
}

Received 1 May 2015; Revised 8 June 2015; Accepted 9 June 2015

Academic Editor: Guang Ye

Copyright ( 2015 Reza Hodjati et al. This is an open access article distributed under the Creative Commons Attribution License, which permits unrestricted use, distribution, and reproduction in any medium, provided the original work is properly cited.

Prepacked aggregate concrete (PAC) is a type of concrete that is placed in two stages where the coarse aggregates are first placed inside the formworks and then the grout is pumped from underneath through a manual pump. Grout properties including density, grout consistency, bleeding, and compressive strength are of great importance in PAC. Such properties could be improved by application of pozzolanic materials like palm oil fuel ash. This paper is aimed at finding the most optimum percentage of POFA replacement by weight of cement. It was concluded that 30\% POFA replacement yielded the most optimum results.

\section{Introduction}

The significance of using prepacked aggregate concrete (PAC) lies within its two-stage placing method. Once the coarse aggregates are placed inside the formwork and then the pumping procedure begins by applying either a manual or a mechanical pump, the role of density, grout consistency, bleeding, and compressive strength of the grout cannot be ignored. The grout is made of cement, sand, and water along with mineral or chemical admixtures to improve the quality of grout and the cement consumption through using pozzolanic materials including different ashes. For the purpose of reducing the cement consumption of the mix, the pozzolanic material named palm oil fuel ash (POFA) was incorporated to reduce the cement consumption and hence reduce the heat of hydration along with improved grout workability.

Palm oil fuel ash is a pozzolanic material which is a byproduct of burning palm oil husk and palm kernel shell in palm oil mill boilers. Based on the specifications of ASTM C618-94a [1], POFA could be classified as a pozzolanic material. Based on previous work, it is evident that the pozzolanic properties of POFA make it a good alternative for fly ash either in lab or in real world projects [2]. Another advantage of using the pozzolanic material POFA is attributed to its environmental hazards. It has been proven that POFA is not an environmentally friendly material and production of huge amounts of POFA in countries like Malaysia along with allocation of more budgets and space for disposal of such material poses great threats to the economy and environment of such countries [3]. Meanwhile, around 200 palm oil mills are producing POFA in Malaysia along with production of large sums of ash without being efficiently used and finally dumped without any benefits [4].

Meanwhile, application of Superplasticizer (SP) improves the workability of the grout along with reducing the water/ binder ratio of the mix [5]. Many studies have been conducted on various aspects of grout properties on concrete including the influence of procedures and apparatus measurements [6], mixing effects [7], proportions and admixtures effect [8], and time dependence [9]. According to the literature, there is access to confirmed results. Yet, the discrepancy between reported results by different scientists is evident $[10,11]$.

As the first hydration stage occurs, the physical and surface chemical effects play an important role in the properties of fresh and young concrete. The packing density of particles is the ratio of the solid volume of the particles to the bulk volume of the particles. Since packing density plays a vital role in mortar/PAC performance, the mix design optimization is done through maximizing the packing density of the particle system [12]. By the time the smaller particles fill up the voids within the paste, the packing effect exhibition is demonstrated through the presence of a denser packing within the 
TABLE 1: Chemical structure of OPC versus POFA.

\begin{tabular}{lccccccccc}
\hline Material & $\mathrm{SiO}_{2}$ & $\mathrm{Al}_{2} \mathrm{O}_{3}$ & $\mathrm{Fe}_{2} \mathrm{O}_{3}$ & $\mathrm{CaO}$ & $\mathrm{MgO}$ & $\mathrm{SO}_{3}$ & $\mathrm{~K}_{2} \mathrm{O}$ & $\mathrm{P}_{2} \mathrm{O}_{5}$ & $\mathrm{LOI}$ \\
\hline OPC & 16.4 & 4.24 & 3.53 & 68.3 & 2.39 & 4.39 & 0.22 & 0.38 & 0.112 \\
POFA & 53.5 & 1.9 & 1.1 & 8.3 & 4.1 & 2.7 & 6.5 & 2.4 & 20.9 \\
\hline
\end{tabular}

matrix $[13,14]$. Nevertheless, the compressive strength of concrete based on packing effect and pozzolanic properties of POFA has to be obtained to understand the role of these two variables on compressive strength [15].

In addition to the packing density, workability of the grout in PAC is a function of the surface area of the particle system. Incorporation of highly fine fillers including ground pulverized fuel ash, silica fume, superfine ground granulated blast furnace slag, superfine cement (SFC), and limestone fine (LF) could lead to a decrease in concrete flowability as a result of increased particle system surface area. Not only does addition of ultrafine palm oil fuel ash to the grout improve its compressive strength, but also it contributes to improved packing effect for the PAC. This could result from the extreme fineness of POFA which improves the mechanical properties of concrete as a result of improved density and larger surface area. On the other hand, larger POFA particles could reduce the workability of the grout as a result of increased surface area. Once the desired POFA fineness is achieved ( $45 \mu \mathrm{m})$, there will be a significant increase in blended cement compressive strength which is attributed to nucleation effect, hydration reaction, and pozzolanic reaction. The hydration process is the result of reaction between chemical constituents in cement and water while the pozzolanic reaction stems from the reaction of $\mathrm{Ca}(\mathrm{OH})_{2}$ with $\mathrm{SiO}_{2}$ and $\mathrm{Al}_{2} \mathrm{O}_{3}$ from palm oil fuel ash which results in the increased production of C-S-H gel. Therefore, coarse POFA possesses a slower pozzolanic reaction compared to that of ultrafine POFA [16, 17]. Method and duration of curing greatly influence the compressive strength of POFA concrete along with POFA replacement percentage.

\section{Experimental Program}

2.1. Materials. Table 1 demonstrates the chemical structure of the POFA as the pozzolanic material incorporated in this study. Since POFA procurement is done from different mills, different properties for POFA are available in the literature. In this research, POFA procurement was done from Golden Hope Palm Oil Mill at Kahang Mill, Kluang, Johor Bahru, Malaysia. Collection of POFA from the mill along with bringing it to the laboratory was the first step of POFA procurement. Prior to sieving, the ash was dried in the oven for 24 hours. Next, a $300 \mu \mathrm{m}$ sieve was used to remove bigger size or excessive materials from the ash. Next, a Los Angeles abrasion machine having $12 \mathrm{~mm}$ diameter and $800 \mathrm{~mm}$ long steel bars (instead of balls) was used to grind the POFA for 4 hours. After that, a $45 \mu \mathrm{m}$ sieve $(50 \%$ passing) was used to sieve POFA to the desired size for obtaining improved mechanical properties. POFA contains some unburned carbon which gives a grey color to it and by increasing the amount of this unburned carbon, the grey

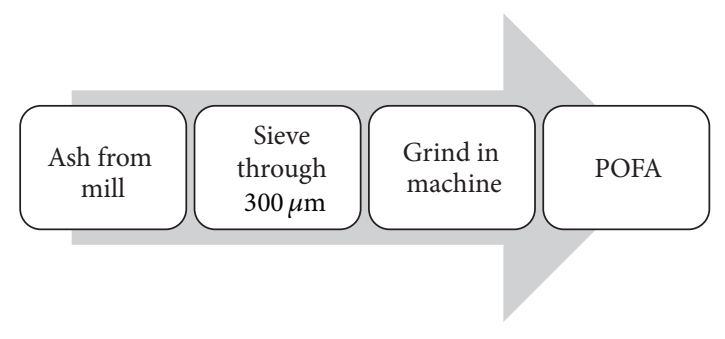

FIgURE 1: Process of procurement of POFA.

color becomes darker. Also its fineness is higher than OPC with a specific gravity of 2.22. A schematic demonstration of POFA procurement is shown in Figure 1.

Furthermore, the reduction rate of $\mathrm{Ca}(\mathrm{OH})_{2}$ is influenced by POFA fineness. Also a lower critical and average pore size is reported for POFA cement paste compared to that of OPC cement paste [18]. Based on Chindaprasirt et al. 2007 [19], POFA utilization could improve the strength and permeability of concrete. The sulfate resistance [20] and chloride resistance of concrete [21] could be improved with POFA. Admixture is an essential part of concrete. In order to improve workability and reduce water/binder ratio, Superplasticizer (SP) was used in the mix to produce a more durable concrete. Even at high water/binder ratios, SP causes better dispersion. Despite the fact that SP facilitates the particle dispersion, there is no clear picture on how SP addition influences porosity and pore size distribution within the cement paste. Based on Khatib and Wild findings, the total intruded pore volume of paste is reduced through addition of SP [22]. There is no indication of dominant pore diameter change within the matrix once SP is included and also there will be an increase in the percentage of pores smaller than $100 \mathrm{~nm}$.

2.2. Mix Proportioning. The two elements that influence the pumpability of the grout are water and sand. Incorporation of appropriate water/binder and binder/sand ratios resulted in making workable grouts for prepacked aggregate concrete to be pumped from underneath into the mass of coarse aggregates. Also performance of the grout was affected by application of the pozzolanic material POFA along with Superplasticizer. Hence, prior to casting, trial grouts were made to obtain the best mix proportion for the grout. For the purpose of making prepacked aggregate concrete specimens, ACI Committee 304 suggests the use of uniform fluid grouts [23]. Grout consistency is the most important factor for evaluation of uniformity of the grout. Therefore, a flow cone suggested by ASTM C939-10 is incorporated [24]. This process involves the calculation of the efflux of a specific volume of grout from a standard flow cone. Three different binder/sand ratios, namely, $1: 1,1: 1.5$, and $1: 2$, along with 


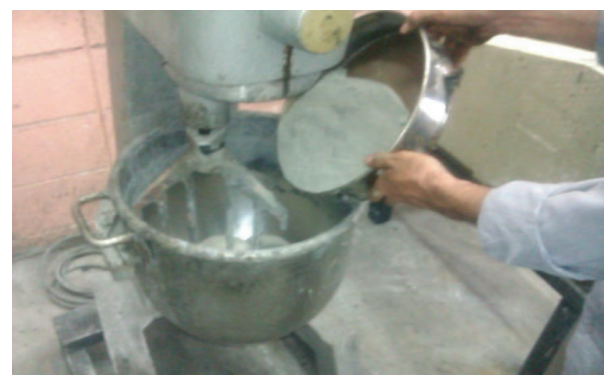

FIGURE 2: Mixing process.

water/binder ratios in the range of 0.43 to 0.47 were used to obtain the most optimum mix proportioning for the grout. It is more economical to use a lower binder/sand ratio. Yet, workability of the grout is greatly affected as a result of increased sand volume within the matrix. This decreased workability and pumpability will result in a concrete with lower strength. For example, the binder/sand ratio of $1: 2$ has a higher water demand than that of $1: 1$ and $1: 1.5$ due to its higher sand content. Therefore, the binder/sand ratio of 1:2 was ignored and considered inappropriate. Then, for the purpose of finding the optimum binder/sand ratio, trial mixtures with binder/sand ratios of $1: 1$ and $1: 1.5$ were made. This was achieved by comparing their 28 -day compressive strength against their binder/sand ratio and choosing the most appropriate mixture. It was concluded that the binder/sand ratio of $1: 1.5$ would be the most proper ratio. After determination of the optimum binder/sand ratio, the next step was to find the optimum water/binder ratio through making trial mixtures and execution of Flow Cone Test. After making several trial mixtures, it was concluded that water/binder ratios in the range of 0.43 to 0.47 would be acceptable. The mixing process is demonstrated in Figure 2.

2.3. Flow Cone Test. For the purpose of determining the fluidity of grouts incorporated in making prepacked aggregate concrete, Flow Cone Test was conducted. The process involved recording the time of efflux of grout from a standard cone in conformity with ASTM C939-10 [24]. The capacity of the cone is $2000 \mathrm{~mL}$. Yet, in this study, a $1725 \pm 5 \mathrm{~mL}$ cone was used to perform the test. Prior to placing the grout, the cone was soaked for 1 minute in water to provide a moist environment for the grout. Once the grout was poured inside the cone, the stopper was removed from the bottom of the cone and timing process started simultaneously using a stopwatch. By observing the first stop in flow of the grout, the time was recorded as the grout consistency of the mix (Figure 3 ).

2.4. Volume Change Properties and Bleeding. Determination of the bleed water on the surface of the fresh grout used in prepacked aggregate concrete (PAC) was done through this test. The test involved using a graduated cylinder and placing the grout inside. The required instruments for execution of this test included a $1000 \mathrm{~mL}$ glass graduate, a $25 \mathrm{~mL}$ glass graduate, and a thermometer. Each test sample included $1500 \mathrm{~mL}$ of grout based on ASTM C940-10a specifications [25]. Volume measurement began within 3 minutes as soon as

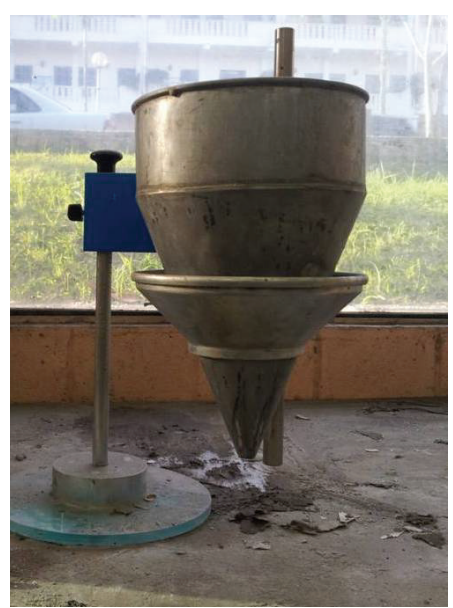

Figure 3: Flow Cone Test.

the mixing process was over. Then, $800 \pm 10 \mathrm{~mL}$ of grout was poured inside a $1000 \mathrm{~mL}$ glass graduate (Figure 4). Next, time and volume recording began. After that, the glass graduate was put on a vibration-free surface and covered for the purpose of minimizing the evaporation of bleed water. The upper surface of the bleed water was the base for readings. The following time intervals were used to record the readings: every 15 minutes during the first hour and every hour until no volume change was recorded. Finally, the bleed water was removed from the top of the grout by tilting the glass and applying a pipet for collecting the bleed water. The precision of recording the volume was $1 \mathrm{~mL}$. The following formulas were used in calculation of the bleeding and expansion of the grout:

Expansion (+) or sedimentation (-),

$$
\%=\frac{V_{2}-V_{1}}{V_{1}} \times 100,
$$

Bleeding,

$$
\%=\frac{V_{2}-V_{g}}{V_{1}} \times 100 .
$$

$V_{1}$ is sample volume at the beginning of the test, $\mathrm{mL}, V_{2}$ is sample volume at intervals taken from the upper surface of bleed water, $\mathrm{mL}$, and $V_{g}$ is grout volume at intervals from the upper surface of the grout, $\mathrm{mL}$.

2.5. Compressive Strength. A "top-restrained" cube was used to perform this test in conformity with ASTM C109/C109 M [26]. Prior to execution of compressive strength test, the grout consistency of the mix was calculated to determine whether it is accepted to perform the compressive strength test or not. If the recorded grout consistency was less than 35 seconds, the execution of compressive strength test was allowed. 72 cubes with dimensions of $70 \times 70 \times 70 \mathrm{~mm}$ were prepared for this test. At first, half of the cubes were filled with the grout and then the grout was stirred by a small piece of metal to remove 


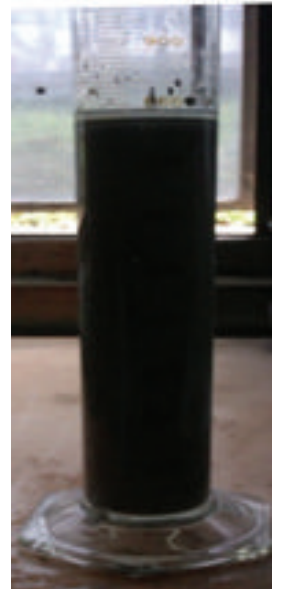

FIgURE 4: Bleeding test.

the entrapped air inside. Then, the molds were completely filled and the surface was finished using a trowel. Next, the specimens were cured according to ASTM C109/C109M and C31/C31M [26, 27]. After that, the specimens were demolded after 24 hours of casting or final set. The compressive strength values were determined after 7 and 28 days according to ASTM C109/C109M [26] (Figure 5).

\section{Results and Discussion}

3.1. Effect of POFA Mechanism on the Microstructure of Grout. Improved mechanical and durability properties are expected for POFA concrete based on the physical and chemical properties of POFA. Once the cement hydration process begins, calcium hydroxide $(\mathrm{C}-\mathrm{H})$ is released and reacts with the amorphous silica of POFA for the purpose of producing calcium-silicate-hydrates (C-S-H). Due to filler effect of POFA which is filling up the spaces between cement grains with its particles, an improved packing effect is reported. This filler effect of POFA within cement particles is similar to that of filling up the voids of coarse aggregates by fine aggregates or filling up the spaces between fine aggregates with that of cement. Furthermore, small additive particles produce large numbers of nucleation sites to precipitate the hydration process. Consequently, smaller $\mathrm{C}-\mathrm{H}$ crystals and accelerated reactions are expected. Reduced number of large pores results from the increased probability of transformation of continuous pores into discontinuous ones. Therefore, there will be an expectation of having denser and more homogeneous microstructures based on the aforementioned mechanisms.

3.2. Grout Consistency. For the purpose of studying the flow characteristics of the grout used in prepacked aggregate concrete (PAC), the influence of different admixtures on grout consistency was investigated in order to find the appropriate mix proportions in accordance with ASTM C939-10 [24]. It is inferred from Figure 6 that grouts with admixtures yielded the lowest grout consistency values indicating more workable grouts. For water/binder ratio of 0.60 , the grout

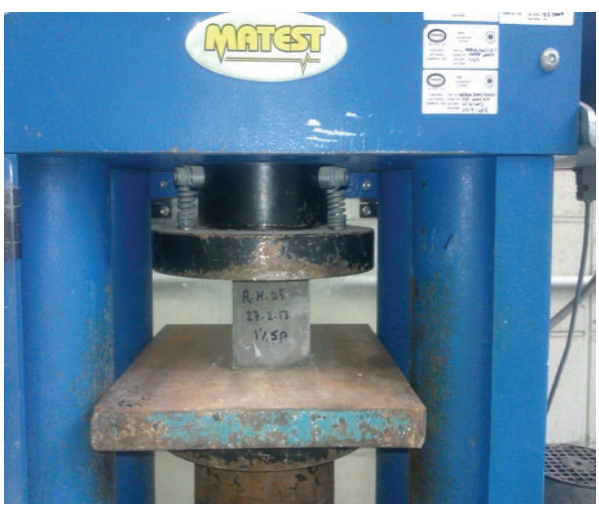

FIGURE 5: Compressive strength test of the grout specimens.

consistency was reported as 14.95 seconds and this amount increased up to 21.95 seconds for lower water/binder ratios (less workable grouts). Application of POFA in the grout increased the workability of the grout and hence decreased the grout consistency values: for $15 \%$ POFA, grout consistency test results were $20.90,17.13,14.84$, and 14.04 seconds for water/binder ratios of $0.45,0.50,0.55$, and 0.60 , respectively, which is an indication of improved workability in the grout due to incorporation of POFA. A higher fluidity was observed when the amount of POFA used in the mix increased to $30 \%$. Once Superplasticizer was used, the fluidity of the grout improved even better. For the same water/binder ratios along with application of $1 \%$ Superplasticizer by weight of cement, the grout consistency values were reported to be 18.76, 15.27, 13.60 , and 13.03 seconds for the previously mentioned grouts without using POFA. The two remaining mixes, namely, 15\% POFA plus SP and 30\% POFA plus SP, were tested as well and they demonstrated better fluidity characteristics compared to previous ones. For 15\% POFA plus SP, the grout consistency values were 17.16, 13.96, 12.61, and 12.06 seconds along with water/binder ratios of $0.45,0.50,0.55$, and 0.60 . Finally, the best fluidity characteristics belonged to $30 \%$ POFA plus SP with water/binder ratios of $0.45,0.50,0.55$, and 0.60 and grout consistency values of 15.32, 12.18, 11.07, and 10.87 seconds, respectively.

3.3. Bleeding Characteristics. The bleeding results for various water/binder ratios of $0.45,0.50,0.55$, and 0.60 and six different mix proportions are demonstrated in Table 2. It is clear that the grout without any admixture yielded the highest percentage of bleeding with 10.38 percent and water/binder ratio of 0.52 . Compared to the mix without any admixtures, mixes with POFA had lower bleeding values which mean that a better performance for grouts with POFA is expected. The bleeding values for 15\% POFA, 30\% POFA, 15\% POFA + SP, and $30 \%$ POFA + SP were 10.00, 8.63, 7.38, and 5.75 percent for water/binder ratios of $0.51,0.50,0.46$, and 0.45 , respectively. Two results are drawn from Table 2 values: firstly, application of POFA and Superplasticizer reduced the bleeding values up to 50 percent which consequently increased the performance of the grout. Secondly, application of Superplasticizer alone also decreased the bleeding values of the grout. 
TABLE 2: Effect of different admixtures on grout properties.

\begin{tabular}{|c|c|c|c|c|c|}
\hline Mix & $\begin{array}{c}\text { Water/binder } \\
\text { ratio }\end{array}$ & $\begin{array}{l}\text { Sand/binder } \\
\text { ratio }\end{array}$ & $\begin{array}{c}\text { Bleeding } \\
\%\end{array}$ & $\begin{array}{c}\text { Sedimentation }(-) \\
\text { expansion }(+)\end{array}$ & $\begin{array}{l}\text { Density } \\
\left(\mathrm{Kg} / \mathrm{m}^{3}\right)\end{array}$ \\
\hline No admixture & 0.52 & 1.5 & 10.38 & -1.13 & 2122 \\
\hline $100 \% \mathrm{OPC}+\mathrm{SP}$ & 0.47 & 1.5 & 9.13 & -0.63 & 2140 \\
\hline $85 \%$ OPC $+15 \%$ POFA & 0.51 & 1.5 & 10.00 & 0.25 & 2127 \\
\hline $70 \%$ OPC + 30\% POFA & 0.5 & 1.5 & 8.63 & 0.75 & 2132 \\
\hline $85 \% \mathrm{OPC}+15 \% \mathrm{POFA}+\mathrm{SP}$ & 0.46 & 1.5 & 7.38 & -0.5 & 2145 \\
\hline $70 \% \mathrm{OPC}+30 \% \mathrm{POFA}+\mathrm{SP}$ & 0.45 & 1.5 & 5.75 & -0.38 & 2151 \\
\hline
\end{tabular}

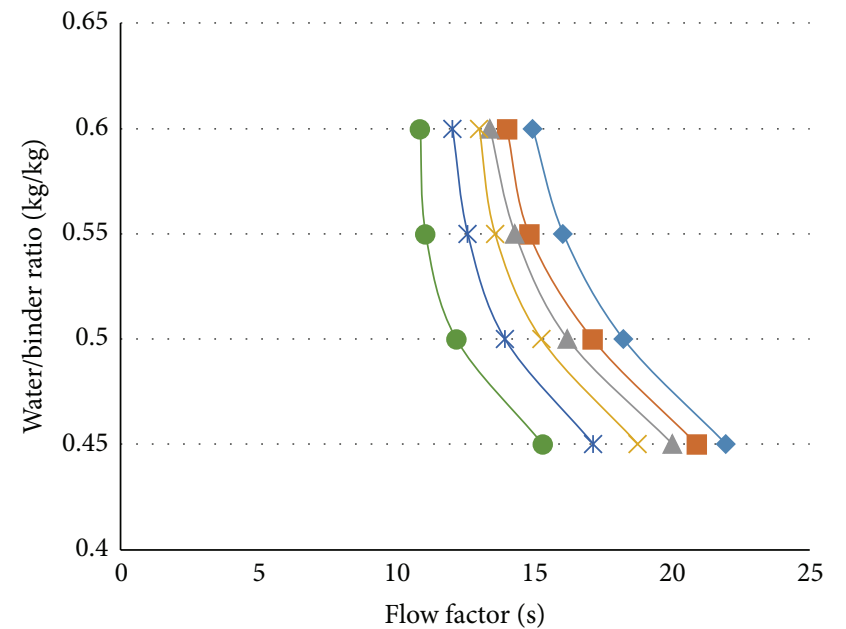

$\begin{array}{ll}- \text { No admixture } & \times \text { Superplasticizer } \\ --15 \% \text { POFA } & * 15 \% \text { POFA + SP } \\ -530 \% \text { POFA } & -30 \% \text { POFA + SP }\end{array}$

FIGURE 6: Grout consistency test of grout for different mixes and binder/sand of $1 / 1.5$.

3.4. Volume Change Properties. Table 2 reveals that grouts without any admixture and grouts with Superplasticizer (SP) had sedimentation while incorporation of POFA did not lead to sedimentation. Grout without any admixture $(\mathrm{w} / \mathrm{b}=0.52)$ had -1.13 percent of sedimentation while incorporation of Superplasticizer (SP) plus a lower water/binder ratio (0.47) led to lower sedimentation with -0.63 percent. This lower sedimentation is in disagreement with the properties of Superplasticizer (SP) which increases sedimentation. In this case, the lower water/binder ratio of 0.47 compared to 0.52 led to lower sedimentation. On the contrary, POFA did not exhibit sedimentation. The $15 \%$ POFA grout $(\mathrm{w} / \mathrm{b}=$ 0.51 ) demonstrated +0.25 percent and the $30 \%$ POFA grout $(\mathrm{w} / \mathrm{b}=0.50)$ demonstrated +0.75 percent expansion. Yet, incorporation of POFA plus Superplasticizer (SP) led to lower sedimentation compared to control grout (without any admixture) and grout with Superplasticizer (SP) only due to the lower water/binder ratios of 0.46 and 0.45 , respectively: 15\% POFA + Superplasticizer (SP) and 30\% POFA + Superplasticizer (SP) demonstrated -0.50 and -0.38 percent sedimentation values, respectively.

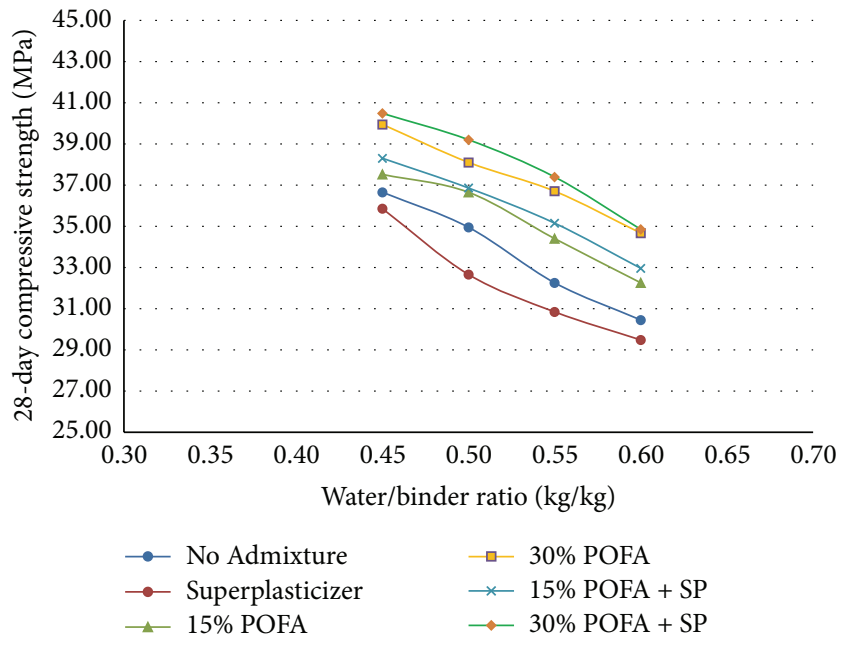

FIGURE 7: Compressive strength of cube specimens $(70 \times 70 \times 70 \mathrm{~mm})$ for different admixtures.

3.5. Density of Grout. Table 2 also indicates the grout density of the six admixtures used in this experiment. Several $70 \times$ $70 \times 70 \mathrm{~mm}$ cube specimens were used to determine the 28 -day density of the grout using different admixtures. The highest density belonged to 30\% POFA + Superplasticizer specimen with $2151 \mathrm{~kg} / \mathrm{m}^{3}$ (water $/$ binder $=0.45$ ). However, the lowest density was for the grout without any admixture with $2122 \mathrm{~kg} / \mathrm{m}^{3}$ (water/binder $=0.52$ ). It is good to mention that application of Superplasticizer and POFA increased the density of the grout which is a good indication of improved grout properties within the matrix. The densities of the grout for SP, $15 \%$ POFA, 30\% POFA, 15\% POFA + SP, and 30\% POFA + SP were $2140,2127,2132,2145$, and $2151 \mathrm{~kg} / \mathrm{m}^{3}$, respectively.

3.6. Compressive Strength of Grout. In order to determine the 28-day compressive strength of the six different grout specimens, a total number of 72 cube specimens $(70 \times 70 \times$ $70 \mathrm{~mm}$ ) were made. Curing of the specimens was done in a water tank for 28 days prior to testing. For each mix proportion, 3 samples were tested and the average value of such tests was reported as the compressive strength of the cubes as demonstrated in Figure 7.

From the graphs, it is inferred that the highest compressive strength for four different water/binder ratios of 0.45 , 
$0.50,0.55$, and 0.60 belongs to $30 \%$ POFA + SP specimen with $40.49,39.21,37.40$, and $34.85 \mathrm{MPa}$, respectively. This maximum compressive strength is attributed to optimum percentage of POFA application (30\% by weight of cement) inside the matrix which increased the density of the grout. The second highest compressive strength also belonged to $30 \%$ POFA specimen with values almost close to maximum values. The lowest values of compressive strength belonged to grout + Superplasticizer specimen with compressive strength values of $35.86,32.66,30.85$, and $29.48 \mathrm{MPa}$ for water/binder ratios of $0.45,0.50,0.55$, and 0.60 , respectively. It is good to mention that in all specimens, by increasing the water/binder ratio, the compressive strength of the specimens decreased eventually.

\section{Conclusions}

It was concluded from this study that the packing effect of the cement paste with POFA increased with an increase in POFA fineness. Therefore, the compressive strength of grout with POFA increases with respect to increased packing effect. Moreover, the grout properties including density, grout consistency, bleeding, and compressive strength were significantly improved using POFA where replacement of $30 \%$ POFA by weight of cement yielded the most optimum grout properties in addition to financial benefits in terms of reduced cement consumption. Also application of POFA improved the density of the grout as well that led to improved mechanical properties and reduced bleeding values along with improved cracking resistance of the grout. Finally, incorporation of Superplasticizer along with POFA yielded better flowability and viscosity properties, higher strength, and higher density which also proves the significance of simultaneous application of POFA and Superplasticizer in the mix.

\section{Conflict of Interests}

The authors declare that there is no conflict of interests regarding the publication of this paper.

\section{Acknowledgment}

The authors wish to acknowledge the help and cooperation received from the technical staff of the Laboratory of Structures and Materials, Universiti Teknologi Malaysia (UTM), in conducting the experimental work. The financial support received from the university is also appreciated.

\section{References}

[1] ASTM C618, "Standard specification for coal fly ash and raw or calcined naturalpozzolan for use mineral admixture in Portland cement concrete," in Annual Book of ASTM Standards, 04.02, pp. 310-313, 2001.

[2] A. S. M. Abdul Awal and S. K. Nguong, "A short-term investigation on high volume palm oil fuel ash (POFA) concrete," in Proceedings of the 35th Conferenece on our World in Concrete and Structure, pp. 185-192, 2010.

[3] M. Ahmad, R. Omar, M. Malek et al., "Compressive strength of palm oil fuel ash concrete," in Proceedings of the International
Conference on Construction and Building Technology, pp. 297306, Kuala Lumpur, Malaysia, 2008.

[4] A. S. M. Abdul Awal and M. W. Hussin, "Effect of palm oil fuel ash in controlling heat of hydration of concrete," Procedia Engineering, vol. 14, pp. 2650-2657, 2011.

[5] S. Guirguis, Superplasticisers in Concrete, Cement and Concrete Associaton of Australia, 1980.

[6] R. Lapasin, A. Papo, and S. Rajgelj, "Flow behavior of fresh cement pastes. A comparison of different rheological instruments and techniques," Cement and Concrete Research, vol. 13, no. 3, pp. 349-356, 1983.

[7] M. Yang and H. M. Jennings, "Influences of mixing methods on the microstructure and rheological behavior of cement paste," Advanced Cement Based Materials, vol. 2, no. 2, pp. 70-78, 1995.

[8] P. F. G. Banfill, "Visco metric study of cement paste containing superplasticizers with a note on experimental techniques," Magazine of Concrete Research, vol. 33, no. 114, pp. 37-47, 1981.

[9] M. Yang and H. M. Jennings, "On the development of rheological properties of cement paste during the induction period," MRS Proceedings, vol. 289, pp. 185-190, 1992.

[10] G. H. Tattersall and P. F. G. Banfill, The Rheology of Fresh Concrete, Pitman Advanced Publishing Program, Boston, Mass, USA, 1983.

[11] P. F. G. Banfill, "Structure and rheology of cement-based systems," MRS Proceedings, vol. 289, pp. 149-160, 1992.

[12] F. de Larrard and T. Sedran, "Optimization of ultra-highperformance concrete by the use of a packing model," Cement and Concrete Research, vol. 24, no. 6, pp. 997-1009, 1994.

[13] G. C. Isaia, A. L. G. Gastaldini, and R. Moraes, "Physical and pozzolanic action of mineral additions on the mechanical strength of high performance concrete," Cement and Concrete Composites, vol. 25, no. 1, pp. 69-76, 2003.

[14] P. K. Mehta and P.-C. C. Aietcin, "Principles underlying production of high-performance concrete," Cement, Concrete and Aggregates, vol. 12, no. 2, pp. 70-78, 1990.

[15] J. Tangpagasit, R. Cheerarot, C. Jaturapitakkul, and K. Kiattikomol, "Packing effect and pozzolanic reaction of fly ash in mortar," Cement and Concrete Research, vol. 35, no. 6, pp. 1145$1151,2005$.

[16] W. Tangchirapat, C. Jaturapitakkul, and K. Kiattikomol, "Compressive strength and expansion of blended cement mortar containing palm oil fuel ash," Journal of Materials in Civil Engineering, vol. 21, no. 8, pp. 426-431, 2009.

[17] V. Sata, C. Jaturapitakkul, and C. Rattanashotinunt, "Compressive strength and heat evolution of concretes containing palm oil fuel ash," Journal of Materials in Civil Engineering, vol. 22, no. 10, pp. 1033-1038, 2010.

[18] W. Kroehong, T. Sinsiri, C. Jaturapitakkul, and P. Chindaprasirt, "Effect of palm oil fuel ash fineness on the microstructure of blended cement paste," Construction and Building Materials, vol. 25, no. 11, pp. 4095-4104, 2011.

[19] P. Chindaprasirt, C. Jaturapitakkul, and T. Sinsiri, "Effect of fly ash fineness on microstructure of blended cement paste," Construction and Building Materials, vol. 21, no. 7, pp. 1534-1541, 2007.

[20] W. Tangchirapat, T. Saeting, C. Jaturapitakkul, K. Kiattikomol, and A. Siripanichgorn, "Use of waste ash from palm oil industry in concrete," Waste Management, vol. 27, no. 1, pp. 81-88, 2007.

[21] P. Chindaprasirt and S. Rukzon, "Strength, porosity and corrosion resistance of ternary blend Portland cement, rice husk ash and fly ash mortar," Construction and Building Materials, vol. 22, no. 8, pp. 1601-1606, 2008. 
[22] J. M. Khatib and S. Wild, "Pore size distribution of metakaolin paste," Cement and Concrete Research, vol. 26, no. 10, pp. 15451553, 1996.

[23] ACI Committee 304, "Guide for the use of preplaced aggregate concrete for structural and mass concrete applications," ACI Journal, vol. 88, no. 6, pp. 650-668, 1997.

[24] ASTM, "Standard test method for flow of grout for preplacedaggregate concrete (flow cone method)," ASTM C939-10, ASTM International, West Conshohocken, Pa, USA, 2010.

[25] American Society For Testing and Materials, ASTM-C940 Standard Test Method for Expansion and Bleeding of Freshly Mixed Grouts for Preplaced-Aggregate Concrete in the Laboratory, American Society For Testing and Materials, West Conshohocken, Pa, USA, 2010.

[26] ASTM, "Standard test method for compressive strength of hydrauliccement mortars (using 2-in. or [50 mm] cube specimens)," in Annual Book of ASTM Standards, Volume 04.01, ASTM C109, pp. 83-88, ASTM, 2001.

[27] American Society For Testing and Materials, ASTM-C31 Standard Practice for Making and Curing Concrete Test Specimens in the Field, American Society for Testing and Materials, West Conshohocken, Pa, USA, 2012. 

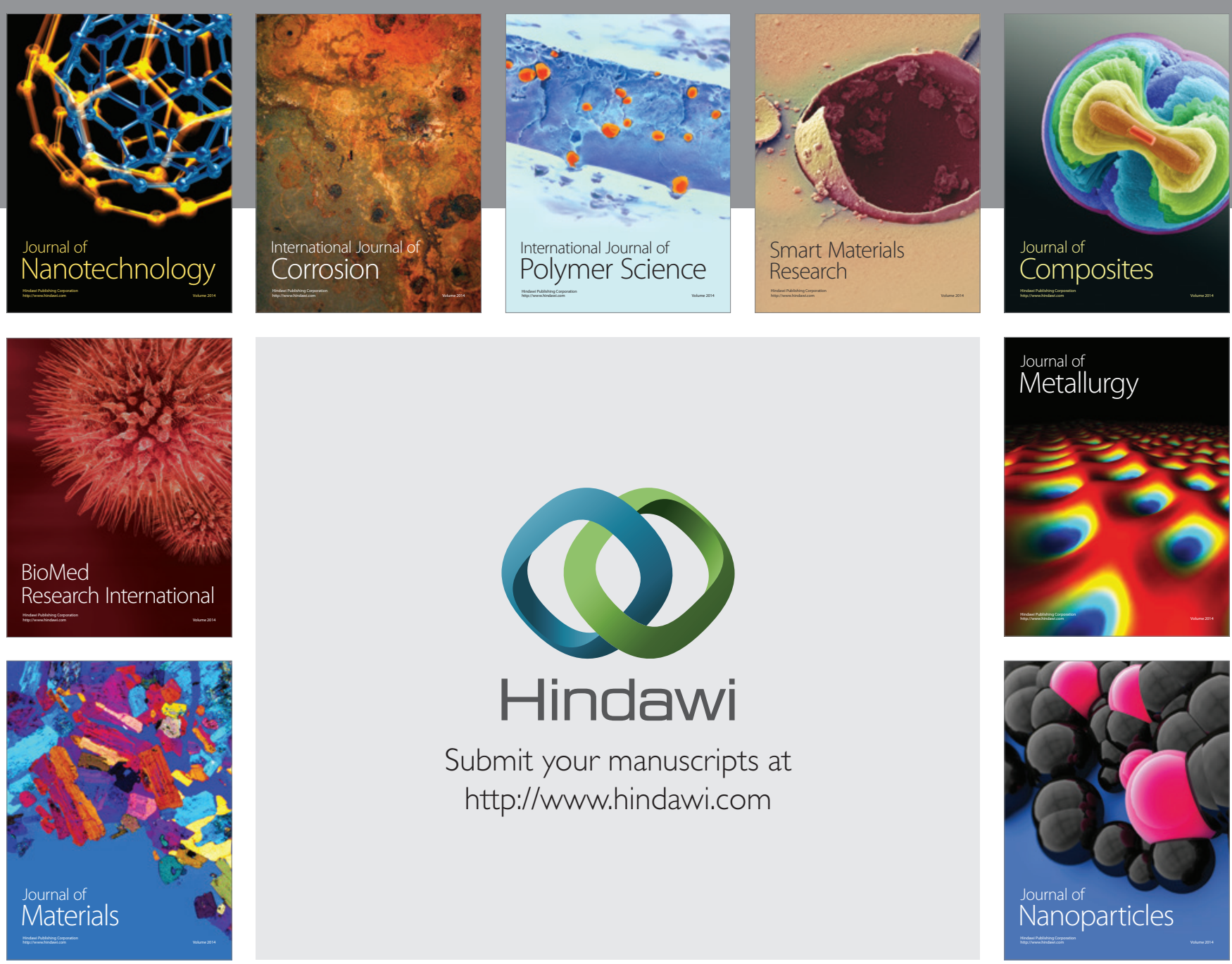

Submit your manuscripts at http://www.hindawi.com
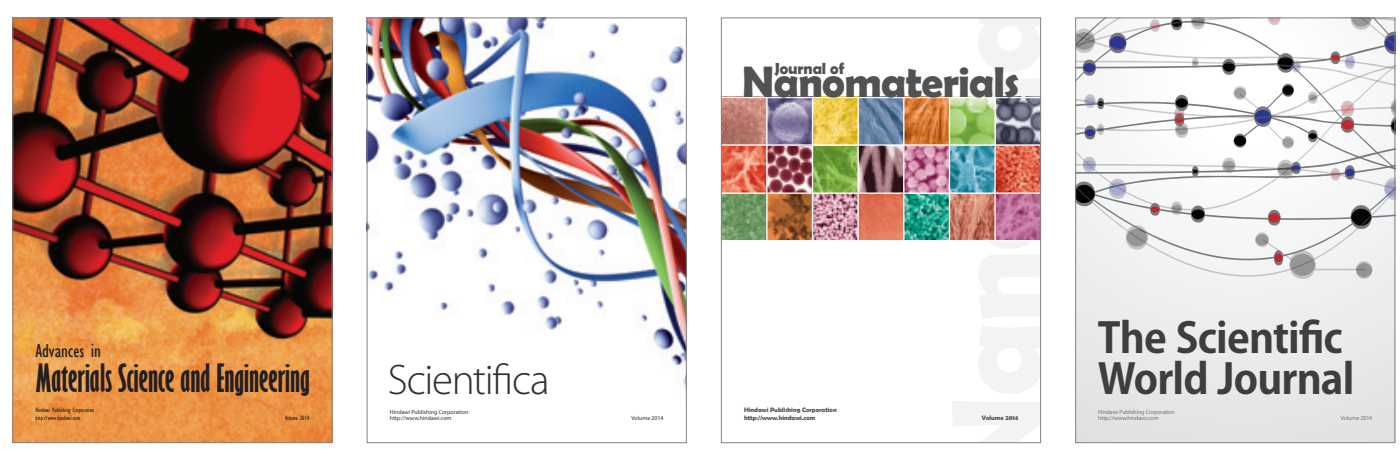

\section{The Scientific World Journal}
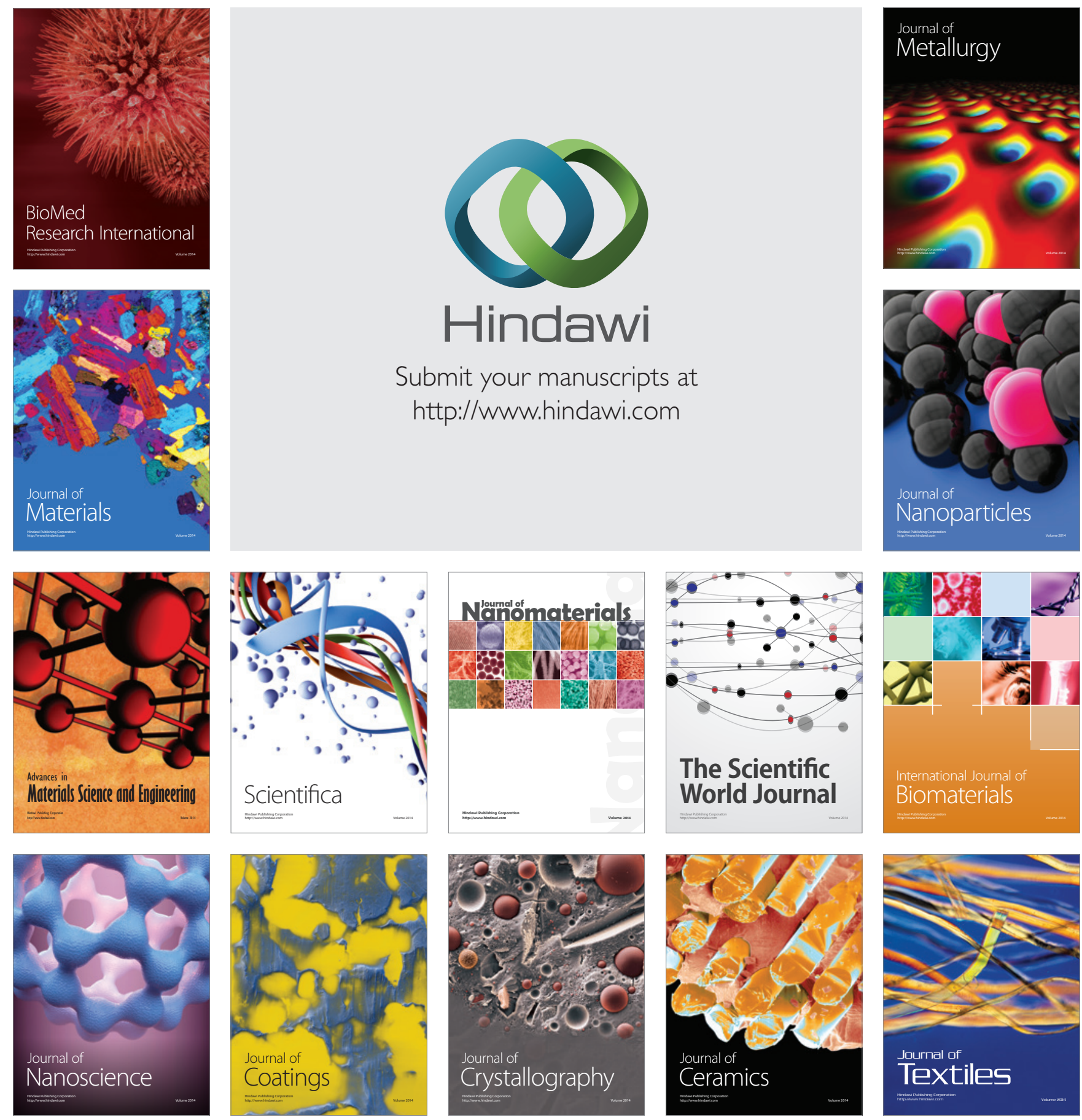